\title{
Functional Morphology of the Feedback Pathway from Area 17 of the Cat Visual Cortex to the Lateral Gen culate Nucleus
}

\author{
Penelope C. Murphy and Adam M. Sillito \\ Department of Visual Science, Institute of Ophthalmology, London EC1 / 9EL, United Kingdom
}

Two approaches were adopted to study the pattern of connectivity between the cat visual cortex and lateral geniculate nucleus. Fourteen individual cortico-geniculate axons were labeled and reconstructed after intracellular or extracellular injection of biocytin into regions of known receptive-field position and ocular dominance preference, and the distribution of boutons from multi-axon clusters was mapped in three dimensions and compared with the locations of strategically placed geniculate recordings made in the same tissue. The results show that the feedback has an accurate retinotopic component but that individual axons are both more extensive and more selective than described previously.

Area 17 feedback axons terminate primarily in layers $A$ and $A 1$, but the distribution of terminal boutons is strongly biased (3:1 ratio) toward the layer that matches their eye preference. Thus, those driven by the contralateral eye preferentially target layer A, and those driven by the ipsilateral eye target layer A1.
Each axon also innervates the perigeniculate nucleus (PGN), but the pattern is otherwise variable, suggesting that there are different axonal classes.

The terminal fields of individual axons are much larger than described previously, with a maximum spread of 500-1500 $\mu \mathrm{m}$. Nevertheless, the projection from a given location in area 17 has a center of maximum terminal density 400-500 $\mu \mathrm{m}$ across, which is in retinotopic correspondence with the aggregate receptive field of the cortical cells of origin. The surrounding zone of relatively sparse boutons, however, must permit corticofugal cells to influence visual processing well beyond the regions over which their own responses summate. It follows that any geniculate cell receives corticofugal input covering an equally extensive area of visual space.

Key words: visual cortex; lateral geniculate nucleus; corticofugal; visual responses; functional connectivity; anterograde tracing
In cats and primates, one of the most prominent inputs to the dorsal lateral geniculate nucleus (dLGN) is a massive feedback pathway from the visual cortex (Höllander, 1972; Hendrickson et al., 1978). In cats, 40-50\% of the synaptic terminals in the geniculate are cortical in origin, compared with only $10-15 \%$ from the retina (Wilson et al., 1984; Montero, 1991). Corticofugal axons make excitatory connections (Ahlsen et al., 1982) with relay cells and local inhibitory neurons (Montero, 1989, 1991; Weber et al., 1989) and thus exert both direct excitatory and indirect suppressive effects over relay cell activity. Judging from the anatomy, therefore, the pathway has the potential for a substantial influence over the transmission of retinal information.

Feedback influences geniculate receptive-field properties in a number of ways, one of the most consistent being an orientationdependent modulation of lateral interactions (Marrocco et al., 1982; Murphy and Sillito, 1987; Sillito et al., 1993). The pathway also influences the temporal structure of geniculo-cortical spike trains, potentially enhancing the transfer of salient information to the cortex (McClurkin et al., 1994; Sillito et al., 1994). Both effects are defined by, and hence sensitive to, the higher-order spatial information encoded in the responses of cortical cells. Consequently, this information is reflected in the response properties of those cells, which in turn provide primary innervation to the cortex (Murphy and Sillito, 1987; Sillito et al., 1993). Feedback,

Received Aug. 1, 1995; revised Nov. 16, 1995; accepted Nov. 24, 1995.

This research was funded by the Medical Research Council. We thank Katherine Graubard for her kind help with the NIH-Image program, and Suzanne Claxton for excellent technical assistance.

Correspondence should be addressed to Penelope C. Murphy, Department of Visual Science, Institute of Ophthalmology, Bath Street, London EC1V 9EL, UK. Copyright (C) 1996 Society for Neuroscience $\quad$ (2270-6474/96/161180-13\$05.00/0 therefore, seems to be an essential element of the circuitry underlying spatial interactions in the visual system.

Understanding of this pathway has been hampered by a lack of anatomical knowledge, in particular of the spatial organization of the projection from individual axons. Previous work provided detailed descriptions of single collaterals (Robson, 1983; Boyapati and Henry, 1984; McCart and Henry, 1994) and ultrastructural elements (Weber et al., 1989; Vidnyánszky and Hámori, 1994) but only partial reconstructions (Robson, 1984). Thus, although we knew that the pathway is broadly retinotopic (Guillery, 1967; Updyke, 1977), we were unable to determine whether a single corticofugal axon distributes boutons only to regions from which it receives input, suggesting a purely local influence, or whether it might contribute to the long-ranging spatial interactions that are a feature of cortical physiology (Allman et al., 1985). Knowing the answer to these questions would facilitate a clearer understanding of the mechanisms underlying the corticofugal influence. Feedback is also involved in binocular processing in the dLGN (Varela and Singer, 1987; Murphy and Sillito, 1989), and again the anatomical substrate is unclear. Information from the two eyes is primarily segregated within the corticofugal pathway (Grieve and Sillito, 1995), yet there seems to be no concomitant anatomical specificity. Rather, the available evidence suggests that corticofugal collaterals innervate indiscriminately geniculate layers driven by the contralateral and ipsilateral eyes (Robson, 1983, 1984; Boyapati and Henry, 1984).

We have used both intracellular pressure and extracellular iontophoretic injections of biocytin to fully label and reconstruct single axons from area 17 and to chart the distribution of boutons arising from restricted cortical loci. The primary aim was to 
provide the first complete description of corticofugal axon morphology. In addition, we have explored the connectivity patterns linking the cortical and geniculate representations of the visual image, in particular the relationship between the response properties of corticofugal cells and both the spread of their axons in retinotopic space and the distribution of their inputs across the geniculate laminae.

\section{MATERIALS AND METHODS}

Experiments were performed on young adult cats ranging in age from 3 months, which is beyond the age at which the corticofugal pathway is thought to reach maturity (Weber and Kalil, 1987), to $>1$ year. The animals were anesthetized $\left(10 \% \mathrm{~N}_{2} \mathrm{O}, 30 \% \mathrm{O}_{2}\right.$, and $0.1-0.4 \%$ halothane), paralyzed (gallamine triethiodide, $10 \mathrm{mg} \cdot \mathrm{kg}^{-1} \cdot \mathrm{hr}^{-1}$ ), and artificially ventilated to maintain end-tidal $\mathrm{CO}_{2}$ levels between 3.8 and $4.2 \%$. Electrocardiogram waveform, intersystolic interval, and the frequency of electroencephalogram spindles were monitored continuously, and the halothane was adjusted to maintain a state of light anesthesia. Wound margins were treated with subcutaneous procaine hydrochloride, and ear bars were coated with antiseptic lignocaine hydrochloride gel. The eyes were treated with atropine methonitrate and phenylephrine hydrochloride, protected with contact lenses, and focused on a semiopaque tangent screen at a distance of $1.14 \mathrm{~m}$. Additional details of our procedures have been described previously (Murphy et al., 1993).

In a small number of cases $(n=3)$, geniculate axons were filled by intracellular injection of cells recorded in layer VI of area 17. Presumptive corticofugal cells were identified using the characteristic receptivefield properties described by Grieve and Sillito (1995) for guidance and were filled by pressure ejection of biocytin (Neuro Phore BH-2 system with pressure module, Medical Systems, Greenvale, NY). The intracellular clectrodes were glass micropipettes containing 2-4\% biocytin (Sigma, St. Inuis, MO) in I $\mathrm{M}$ potassium chloride and $0.05 \mathrm{M}$ Tris buffer (Sigma), pH 7.2, with an impedance of 70-100 M $\Omega$. They had a short shank and a relatively blunt profile to facilitate ejection, but to fill an entire corticofugal axon nevertheless required at least 10 min at $25 \mathrm{psi}$. In contrast. local elements could be labeled fully within $30-60 \mathrm{sec}$ using this method. A larger number of axons were labeled by extracellular injection, using a method adapted from Deschênes and Pinault (1993). Small currents $(+180-200 \mathrm{nA})$ were passed over a long period $(50-70 \mathrm{~min})$ using a $1 \mathrm{sec}$ on/1 sec off cycle through biocytin-filled micropipettes with a $1 \mu \mathrm{m}$ tip. Using this technique, we generally labeled between 1 and 10 individual cells (Fig. 1) from which a smaller number of axons projected toward the thalamus. Most faded from view at the first branch-point, leaving a minority that could be fully visualized. Reconstruction of an axon was attempted only if it had well labeled intrageniculate collaterals that were clearly distinguishable from other processes arising from the same injection site. The receptive fields of injected cells were mapped and classified before filling, as were those of representative cells recorded at the extracellular injection sites. In a majority of cases, extracellular injections were made in the center of ocular dominance columns to label the axons of monocular or nearly monocular cells [ocular dominance $(\mathrm{OD})$ categories $1 / 7$ or $2 / 6$ ]. A number of 100 to $200 \mu \mathrm{m}$ diameter extracellular injections were also made, with the deliberate intention of labeling a larger number of corticofugal axons. In these cases, tungsten clectrodes were used to record from dLGN cells within and beyond the perimeter of the expected termination zone. The dLGN recording sites and their corresponding visual-field locations were used in conjunction with the retinotopic maps of Sanderson (1971b) to provide an accurate estimate of the spread of the corticofugal terminals with respect to visual space. Great care was taken to minimize residual eye movements, and the locations of several key retinal landmarks were used to check and correct for any drift that occurred between the times when the cortical and the dLGN receptive fields were mapped.

After an 18-40 hr survival period, animals were anesthetized deeply and perfused transcardially with $4 \%$ paraformaldehyde and $0.5 \%$ glutaraldehyde in $0.1 \mathrm{~m}$ sodium phosphate buffer, $\mathrm{pH} 7.2-7.4$. The thalamus was stereotaxically cut at an angle of $20^{\circ}$ anterior-to-posterior to establish a cutting plane parallel to the geniculate projection columns in the region of interest, and then dLGN and visual cortex were infiltrated with $20 \%$ sucrose as a cryoprotective measure and sectioned at $40 \mu \mathrm{m}$ on a freezing microtome. Sections were processed according to published methods (Adams, 1981; Horikawa and Armstrong, 1988) for the detection of biocytin. Cortical sections were counterstained with neutral red to estab-

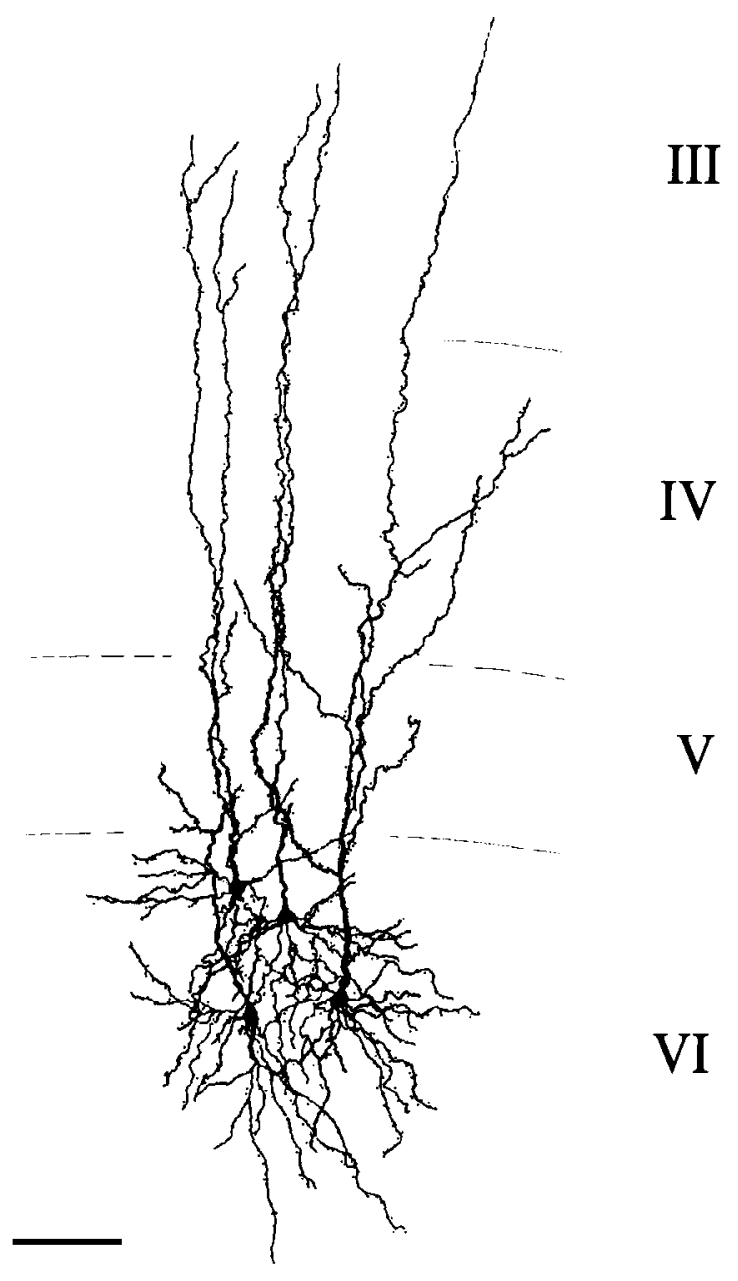

Figure 1. An extracellular injection site within layer $V I$ of area 17. Extracellular iontophoresis of biocytin produced a Golgi-like label of four pyramidal cells, of which one gave rise to the corticofugal axon illustrated at the left of Figure 3, and two nonpyramidal cells (not shown). Although the cells and their processes are darkly stained, the surrounding neuropil is entirely free of label. Scale bar, $100 \mu \mathrm{m}$.

lish laminar and areal borders. Geniculate sections were mounted, dehydrated, and coverslipped, and the stained axons were drawn and reconstructed using a camera lucida. Particular attention was paid to the distribution of terminal swellings within layers $\mathrm{A}$ and Al. The nonspecific background staining generally was sufficient to show the borders of the $A$ laminae with clarity; however, neighboring sections and, where necessary, selected sections from within the axonal arbors were also counterstained after completion of the drawings. In the case of the larger injections, the locations of terminal swellings within a single layer ( $\mathrm{A}$ or $\mathrm{Al})$ and the location of lesions representing the sites at which dLGN cells were recorded were mapped and digitized section by section. The individual files were then stacked with appropriate spacing to give a threedimensional representation of the data using the NIH-lmage program (version 1.4, available from zippy.nimh.nih.edu via FTP) and rotated to give a surface view.

The distances between penetrations within the dLGN werc measurcd accurately during the recording experiments and from the histological records and used to estimate tissue shrinkage. All distances given in the illustrations and text are $-95 \%$ of the in vivo values. The intrageniculate axons are extremely fine and delicate and have a wide spread. To reduce the final reconstructions to a size suitable for publication, it was necessary to exaggerate greatly the diameter of even the thickest branches, the size of terminal swellings, and the length of their stalks. A more realistic depiction of individual collaterals, however, can be found clsewhere (Guillery, 1966; Robson, 1983, 1984; Boyapati and Henry, 1984; McCart and Henry, 1994). 


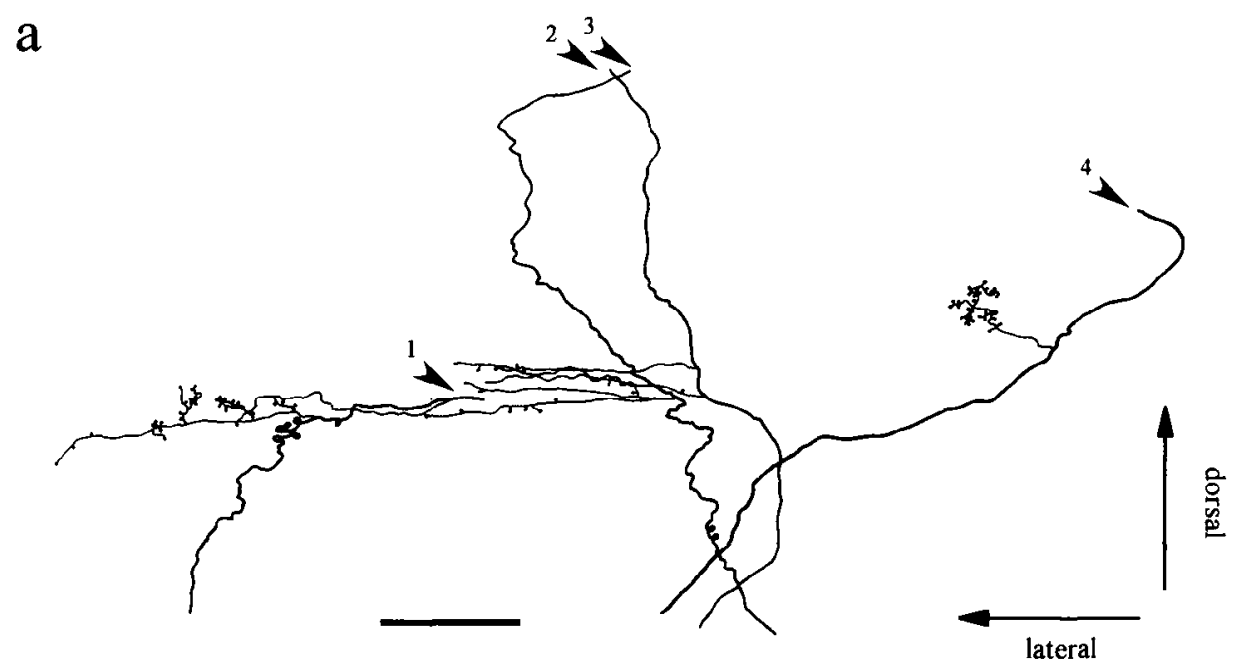

Figure 2. Innervation of the TRN. $a$, Four axons (arrowheads) arising from a single, highly restricted cortical injection. As the axons course through TRN, each gives rise to one or two fine collaterals bearing a small number of terminal boutons. The terminals arising from axons 2 and 3 are intermingled; those from axons $I$ and 4 are more widely separated. $b$, Location with respect to the lateral geniculate nucleus. $c$, Distribution of terminal houtons as viewed from above. Note that the innervation forms a narrow cylinder angled in a caudo-medial to rostro-lateral plane, extending a total distance of $\sim 700 \mu \mathrm{m}$. Scale bars, $100 \mu \mathrm{m}$. $b$

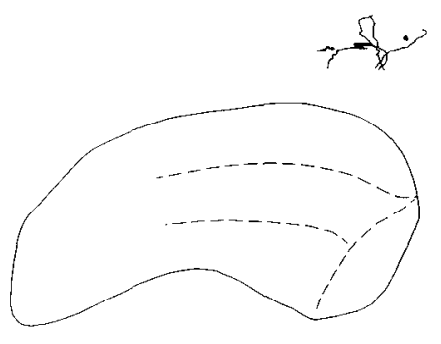

C

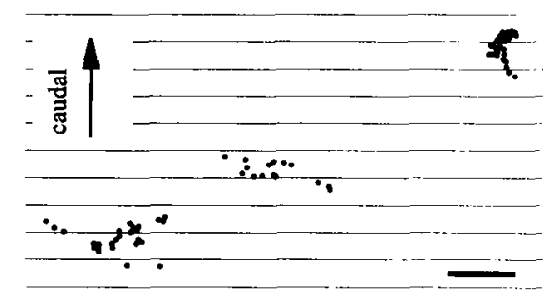

\section{RESULTS}

The data reported below derive from a population of 14 fully reconstructed area 17 corticofugal axons, all of which had receptive fields within $6^{\circ}$ of the area centralis. Of these, one had a fully binocular response (OD 4), whereas the rest arose from the monocular regions at the center of contralaterally ( 7 axons) or ipsilaterally ( 6 axons) driven ocular dominance columns. An additional axon, which formed a sparse but widespread arborization, has been excluded from quantitative analysis because it seemed to be labeled inadequately. A large number of partially labeled axons were also traced and cxamined as far as the dLGN border.

\section{General description}

The main axons vary in diameter from $\sim 0.4$ to $1.0 \mu \mathrm{m}$, as measured at the base of the subcortical white matter. The cells of origin presumably belong, therefore, to the type 1 category described by Katz (1987). En route to the appropriate region of the dI GN, half of the axons give off a few fine collaterals hearing terminal boutons as they pass through the thalamic reticular nucleus (TRN). It is of interest to note that axons from a single, highly localized cortical injection site frequently innervate regions of the TRN that are well separated, predominantly in the caudomedial and rostro-lateral direction (Fig. 2). Some of the reconstructed axons split into two branches at this point, both of which project to the same target region of the dLGN. Each of the reconstructed axons innervates the region of the perigeniculate nucleus (PGN) immediately above, and hence retinotopically corresponding to, that of the intrageniculate arborization. In both the PGN and the TRN, single axons may give rise to two types of collateral. One is similar to that seen within the body of the dLGN, whereas the other has relatively large boutons that are frequently attached to the stem of the axon, giving them an almost beaded appearance.
The intrageniculate collaterals are typical of the type 1 axons described by Guillery (1966). They are fine and smooth and bear small terminal boutons carried on the end of short stalks or, occasionally, attached directly to the axon stem. The collaterals arising from an individual axon can vary greatly in diameter, from main descending branches approaching $0.5 \mu \mathrm{m}$ across to sidebranches that are close to the resolution limits of the light microscope. Thicker axons tend to have thicker primary branches, but otherwise the caliber and appearance of an individual collateral give no indication of the size or spread of its parent axon.

\section{Distribution of boutons throughout the geniculate laminae}

Each axon innervates the magnocellular layers $\mathrm{A}$ and $\mathrm{A} 1$. Beyond that, the pattern is variable, with some axons reaching the magnocellular and parvocellular $\mathrm{C}$ layers and some giving an additional input to the medial interlaminar nucleus (MIN). Hence, a single axon can project to all of the layers and all of the subregions of the dLGN complex that are known to receive area 17 input (Updyke, 1977). One such example is shown in Figure 3 (left). This axon originates from one of four pyramidal cells that were stained by the extracellular injection of biocytin illustrated in Figure 1. No attempt has been made to trace the axon back to an individual cell body, but the four candidates all lie within $50 \mu \mathrm{m}$ of the location of the electrode tip and, therefore, are likely to have shared the same ocular dominance bias. The labeled axon splits into two branches in the upper regions of the PGN and then begins to divide again at the border of layer $\mathrm{A}$ and bear terminal boutons. The collaterals fan out in layer $A$ and then descend through layers $\mathrm{A} 1$ and magnocellular $\mathrm{C}$, in some cases reaching the parvocellular $\mathrm{C}$ layers. They continue to branch repeatedly and to give off finer side-branches throughout their length. Although many of the main branches run approximately perpendic- 


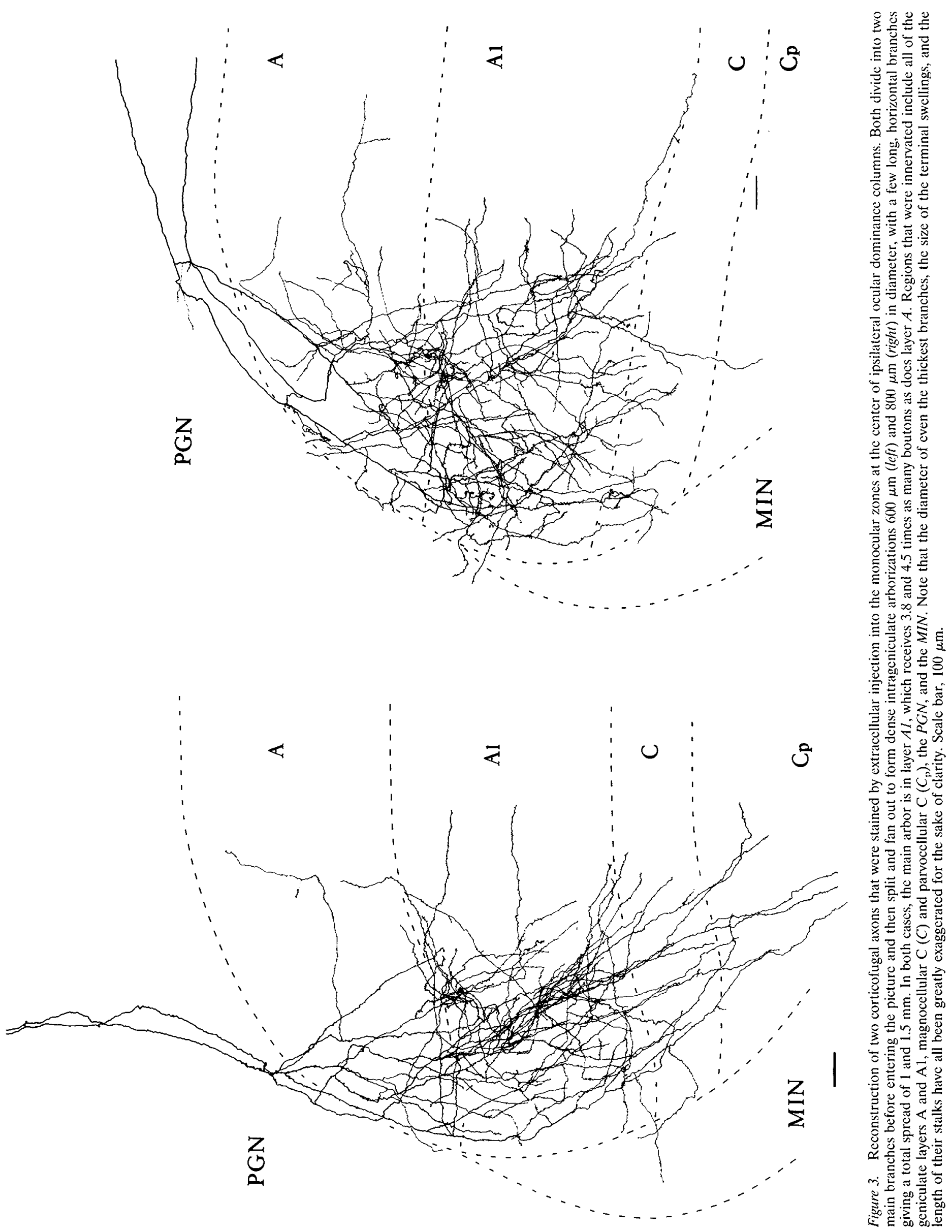




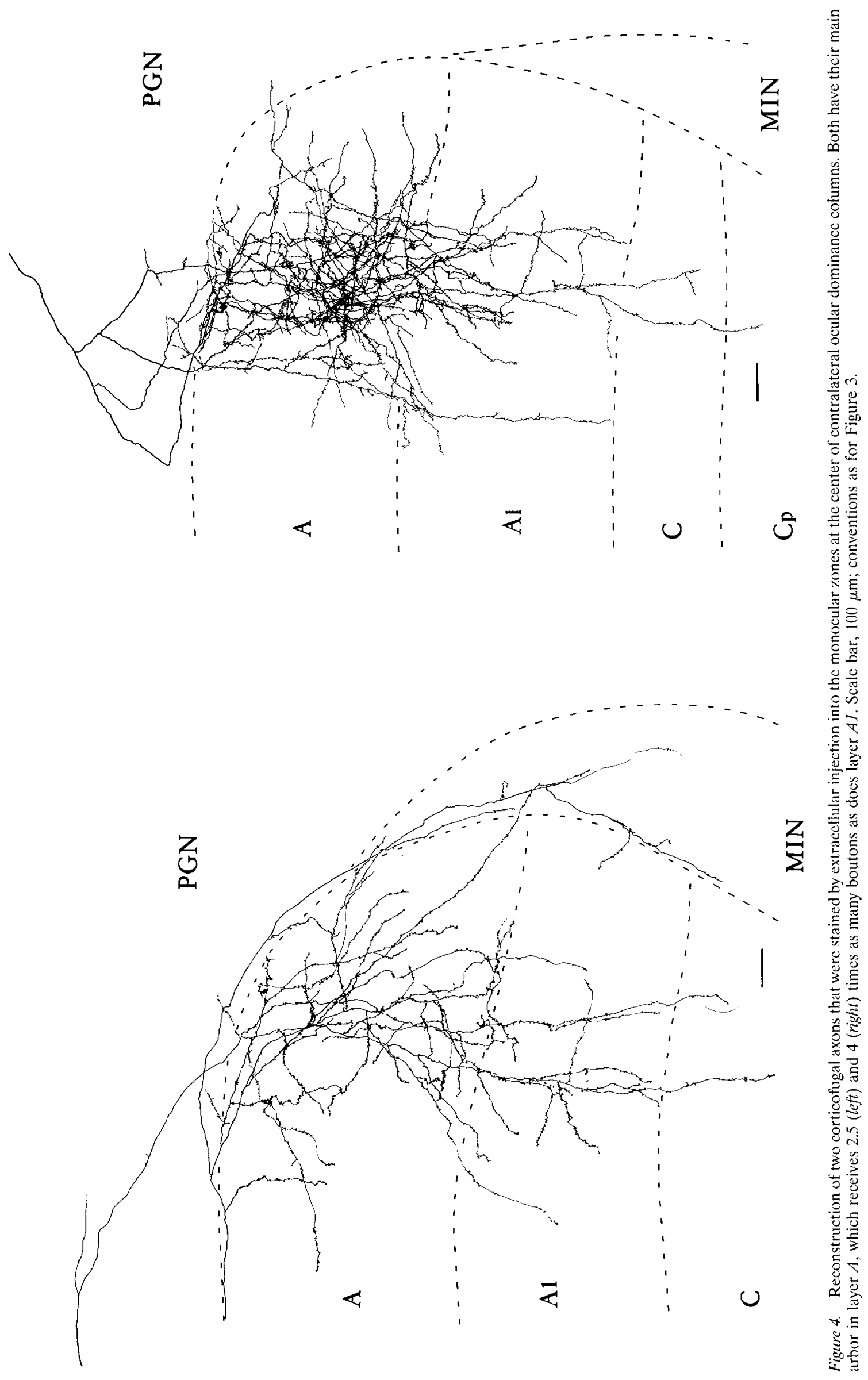




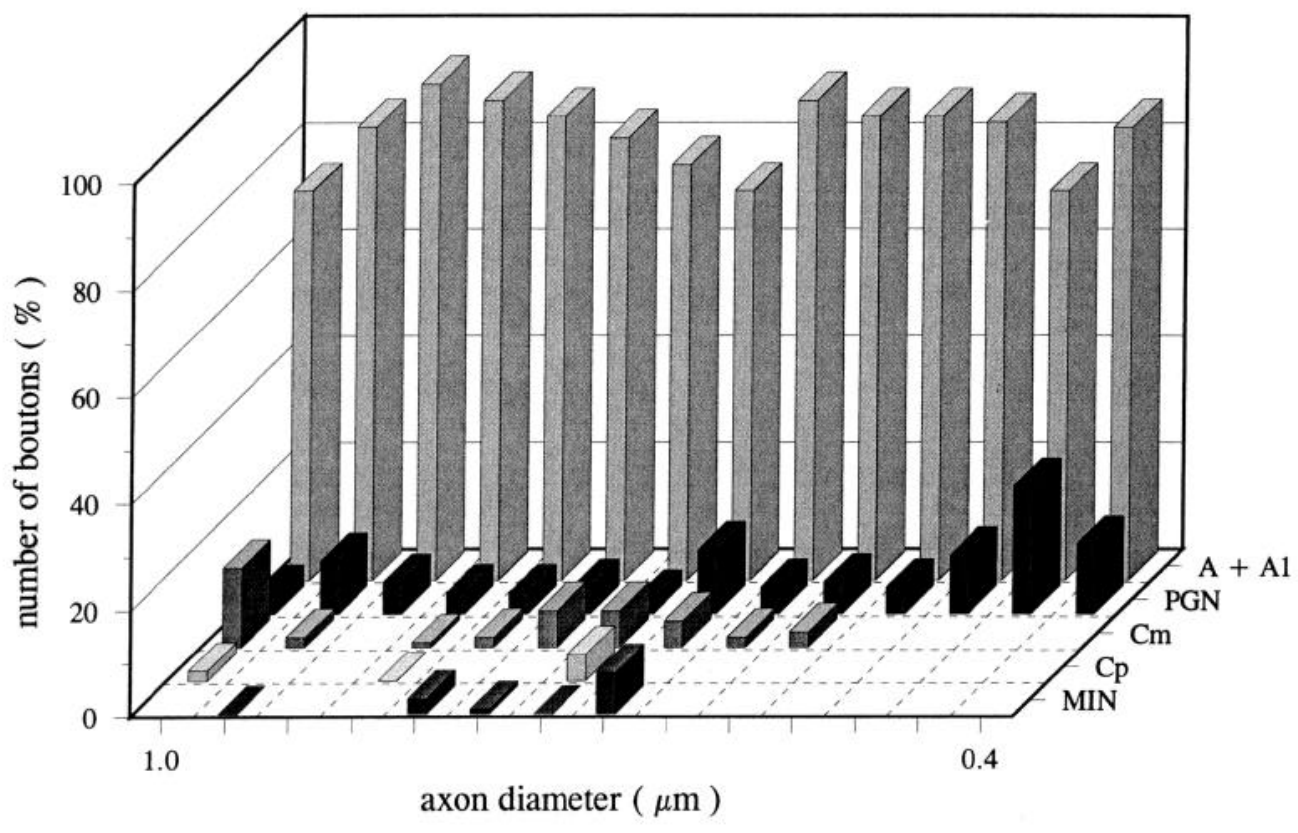

a

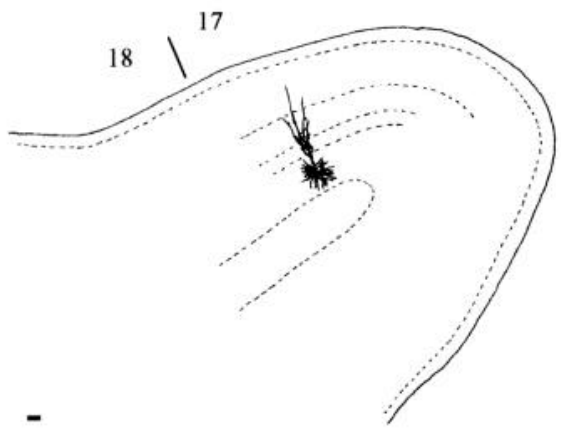

b

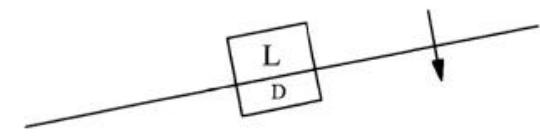

A1

$1 \mathrm{deg}$
Figure 5. Distribution of area 17 corticofugal boutons. The graph shows the number of boutons from each of the 14 fully reconstructed axons, expressed as a percentage of the total for that axon, that was found within the main layers and compartments of the dLGN complex. The data have been ranked such that the thickest axon is to the left and the thinnest to the right. Only the $P G N$ and $A$ laminae receive input from every axon, whereas the distribution to other compartments is variable. A great majority of boutons (73-93\%), however, are found within the A layers. Reading from the left, the total number of boutons for each axon is $1321,2183,3260$, 2636, 2026, 4259, 3330, 2523, 4128, 1067, $1169,1326,1723$, and 1127 . Cm, magnocellular c; all other abbreviations as for Figure 3. 
Figure 7. Distribution of area 17 corticofugal boutons in the A laminae for each of the 14 fully reconstructed axons. The data are divided into five categories that have a reciprocal relationship; i.e., $80-100 \%$ in layer A corresponds to $0-20 \%$ in layer $\mathrm{A} 1$ and vice versa. Although each axon innervates both the contralaterally driven layer $\mathrm{A}$ and the ipsilaterally driven layer A1, most show a marked bias toward the layer that matches their ocular dominance preference. Gray, white, and black bars: contralaterally driven, binocular, and ipsilaterally driven axons.

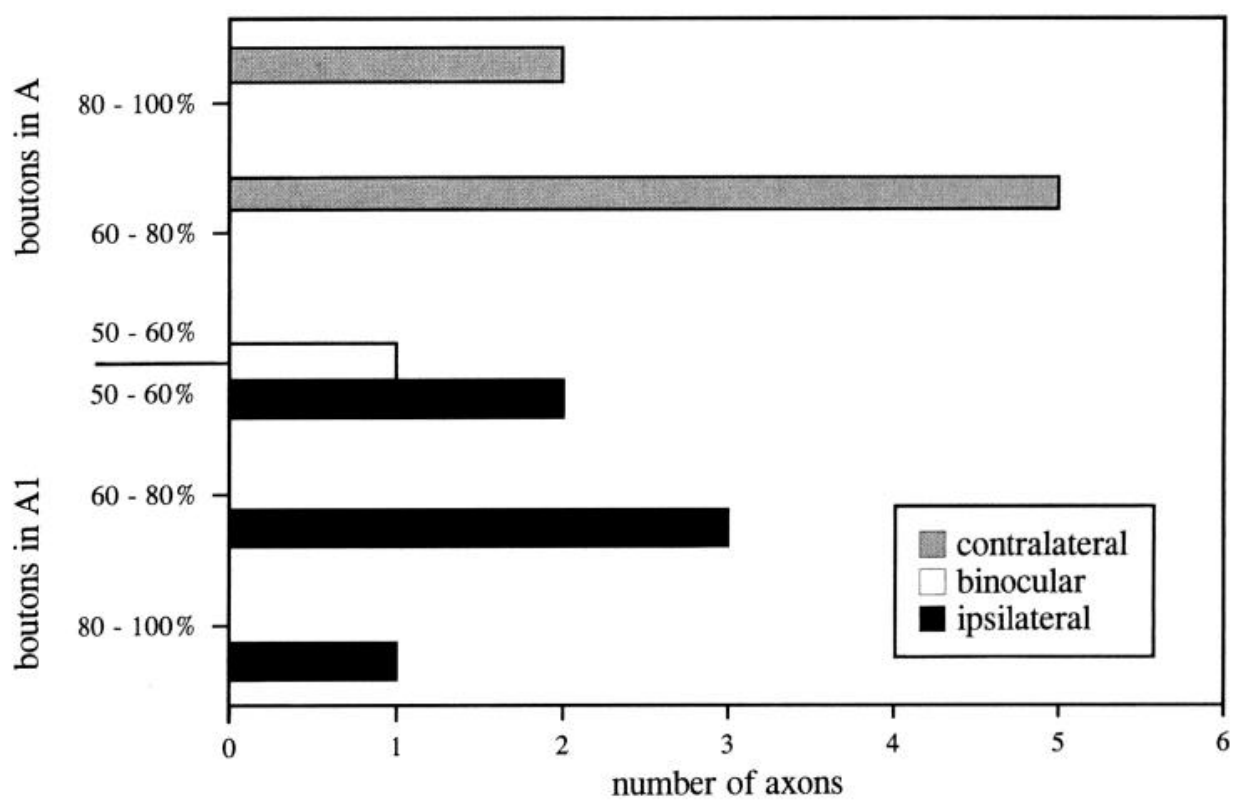

spaced up to $700 \mu \mathrm{m}$ apart, of which one reaches the parvocellular C layers and another branches into MIN. Nevertheless, it bears a total of only 607 boutons. This is because it gives off relatively few visible side-branches, and many of those are so thin and pale as to be impossible to trace beyond a single section. Overall, therefore, this seems to be the framework of a large axon of which only the major collaterals have labeled adequately, although the possibility that it represents a separate class cannot be ignored.

\section{Comparison of the inputs to layers A and A1}

Although each of the reconstructed axons projects to both layers A and A1, a majority of those arising from both monocular (OD $1 / 7$ ) and unequal binocular (OD 2/6) regions of the cortex show a marked bias toward the layer that matches their eye preference. Thus, for example, the two axons illustrated in Figure 3 come from the monocular regions at the center of ipsilateral eye ocular dominance columns, and they have 3.8 (left) and 4.6 (right) times as many boutons in the ipsilaterally driven layer A1 as compared with the contralaterally driven layer A. Note in particular that the axon on the right has three main branches, and although it is difficult to illustrate accurately in two dimensions, two partially bypass layer A before entering the dLGN at a point on the medial border, whereas the third passes through most of the layer before beginning to divide and fan out. All three contribute to an extensive network of fibers in layer A1. In contrast, the axons in Figure 4 originated in contralateral eye ocular dominance columns. Both have their main arborization in layer A, which receives 2.5 (left) and 4 (right) times as many boutons as does layer A1. In both cases, only a small number of main collaterals penetrate into layer A1, and many branches terminate just before, or soon after, crossing the interlaminar zone.

Most cortico-geniculate projection cells are either fully monocular or strongly biased toward one eye (Grieve and Sillito, 1995). Consistent with this is the fact that axons arising from regions of unequal binocularity tend to show as great a preference for the layer (A or A1) that provides their preferred input as do those from monocular zones. Therefore, no attempt has been made to stain binocular cells with extracellular injections, and the one binocular axon (OD 4) so far recovered was stained intracellu-

The fifteenth axon has three main descending collaterals 


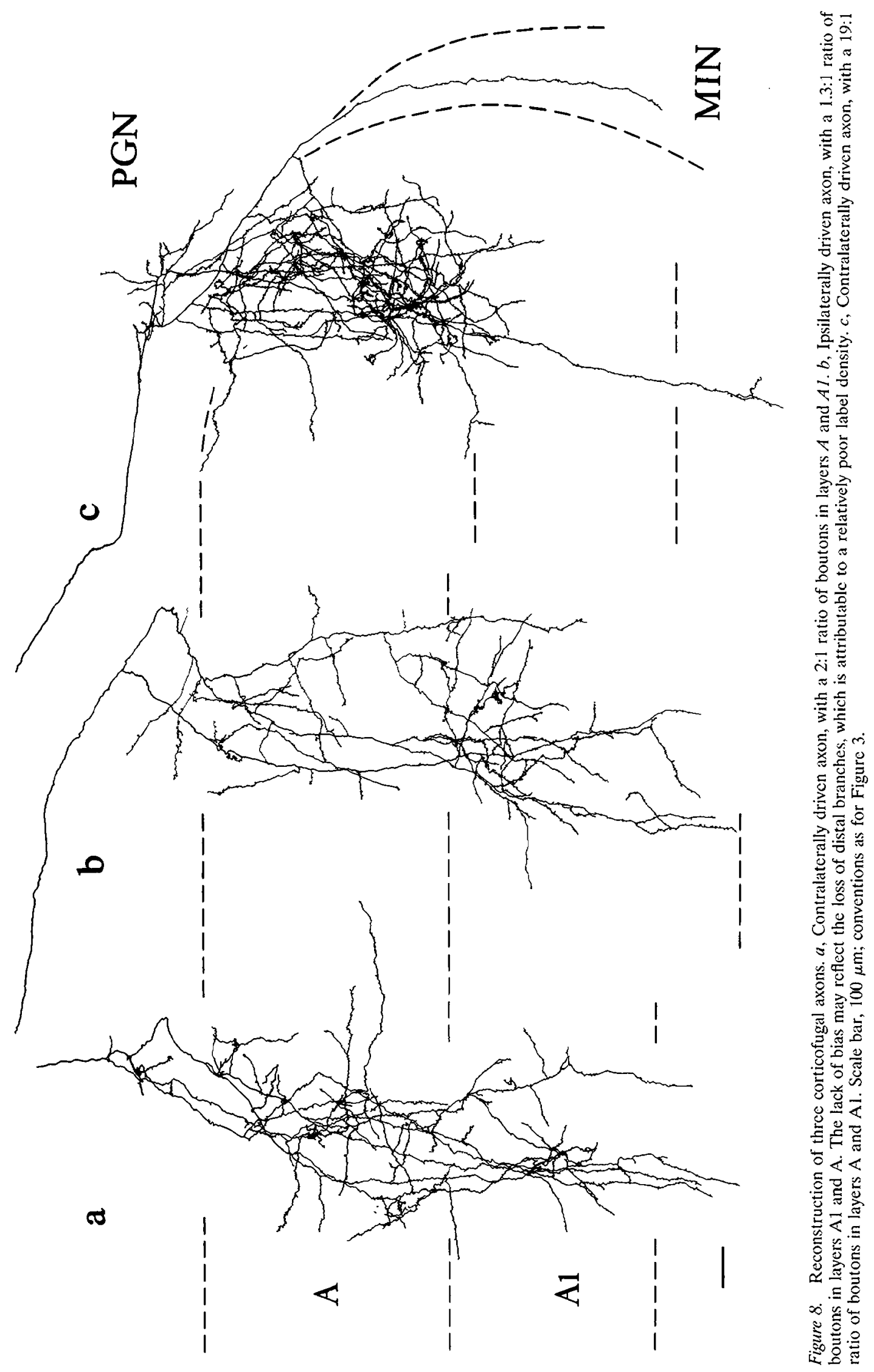


larly. The cell body was recovered from layer VI of area 17 , close to the $17 / 18$ border (Fig. $6 a$ ). The cell was tightly orientationtuned and totally directional, and it had a simple receptive field with clearly separable light and dark discharge zones (Fig. 6b). It responded well to a short $\left(2^{\circ}\right)$ bar, which is typical of the area 17 corticofugal population (Grieve and Sillito, 1995). Its dendritic morphology is consistent with the type 1 cells described by Katz (1987) as having a spherical basal dendritic field and an apical dendrite that divides in layer $\mathrm{V}$ and terminates in layer IV and lower layer III. The intrinsic axon of this cell terminates principally within layer IV and covers a region $800-1000 \mu \mathrm{m}$ across. The terminal arborization of the corticofugal axon is mostly confined to layers $\mathrm{A}$ and $\mathrm{Al}$ of the dLGN (Fig. $6 c$ ), which it innervates in a 1:1.4 ratio. It therefore shows little bias toward either layer.

The distribution of terminals in the A laminac for each of the reconstructed axons is given in Figure 7 . All of the seven axons with contralateral eye preference had a substantial bias toward layer $A$, with $>60 \%$ of their A laminar boutons in that layer. The most extreme example had 19 times as many in layer A as in A1 (Fig. $8 \mathrm{c}$ ). In contrast, 4 of 6 axons with ipsilateral eye preference had an equally strong bias toward layer $A 1$. The two unbiased ipsilaterally driven (Fig. 8b) and one of the Inost biased contralaterally driven axons were thin and relatively poorly labeled. It is therefore possible that the more distal branches, a majority of which would necessarily have been in layer A1, were not fully visualized in these cases. Thus, these distributions may have been artificially biased toward layer $\mathrm{A}$, with each of the three axons in reality belonging in the appropriate $60-80 \%$ category. Even so, the data fall into two entirely separate groups, which are strongly correlated with eye preference (point-biserial correlation coefficient $r_{\mathrm{pl}},-0.91$ ). When the population is taken as a whole, the 13 monocular axons have $73 \%$ (range $55-95 \pm 3 \%$ ) of their layer A and A1 terminals in the "appropriate" layer compared with $27 \%$ in the inappropriate layer.

\section{Lateral spread of the corticofugal input}

It is clear from the preceding figures that corticofugal axons form larger arbors than has been demonstrated previously (Robson, 1984). Many thicker collaterals, which more readily catch the eye when tissue labeled by a bulk injection of tracer is examined, run vertically through the dLGN and therefore follow the retinotopic lines of projection (Sanderson, 1971b). Each axon gives rise to many of these descending collaterals, however, and they are spread over a wide region rather than constrained to a narrow column. Furthermore, there are also many oblique and horizontal collaterals, some of which project for substantial distances. This is quantified in Figure $9 a$, which shows the mediolateral extent of each of the 14 fully reconstructed axons as well as the partially labeled example mentioned above. Two measures are given: one defined as the central region over which there is a framework of vertically descending collaterals (the "core"), and the other as the maximum tip-to-tip distance covered by the longest-ranging horizontal collaterals. The largest axon in this sample (Fig. 3, right) has a core region $800 \mu \mathrm{m}$ wide and a maximum spread of $1.5 \mathrm{~mm}$, whereas the smallest is confined to a region $290-500 \mu \mathrm{m}$ in diameter. The average figures for the population as a whole are $935 \pm 77$ and $490 \pm 39 \mu \mathrm{m}$.

There is no correlation between the diameter of the parent axon and either the size of the arborization or the total number of boutons (Fig. 9b). There is a good correlation, however, between the latter two measures, because the larger arbors also carry the largest number of boutons. This is particularly so if only the core a

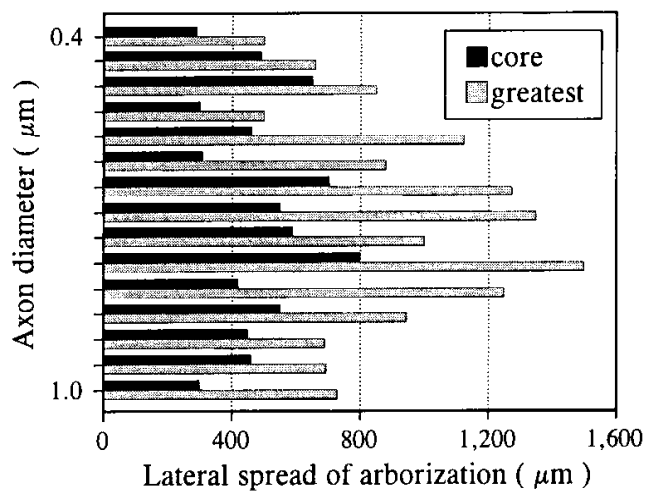

b

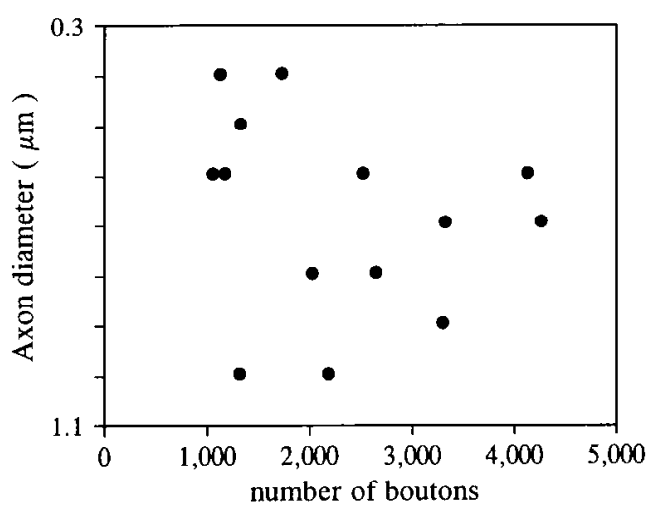

Figurc 9. Graphs showing the mediolateral spread of the arborization (a) and the total number of boutons $(b)$ for each of the reconstructed axons, compared with the diameter of the axon. Data are ranked according to axon diameter, with the thinmest at the $t o p$ and the thickest at the bottom. Core (black bars): central region over which there is a framework of descending axon collaterals; greatest (gray bars): the tip-to-tip spread of the longest-ranging collaterals.

region in the most densely innervated layer is considered $\left(R^{2}=\right.$ $0.54 ; n=14)$. Thus, the overall density of innervation in this region is constant from axon to axon and is independent of arbor size. Even within the core, however, the innervation from any one axon is rather sparse $\left(13,500 \pm 1220\right.$ boutons $\left./ \mathrm{mm}^{3}\right)$, and there is generally no clearly defined central focus of maximal innervation density. Instead, the terminal boutons form an apparently random and patchy distribution, with extensive zones that are entirely free of input. This applies equally well to the axons with narrower arborizations (Fig. 8a), because thcy also carry the smallest number of collaterals and boutons.

\section{Pattern of connectivity between the cortical and geniculate retinotopic maps}

The retinotopic maps of dLGN and cortex are highly nonlinear and, therefore, it is difficult to determine how they interconnect hased on the published maps alone (Sanderson, 1971b; Tusa et al., 1978). For example, a mediolateral distance of $1.5 \mathrm{~mm}$ in the dLGN represents $5^{\circ}$ at an eccentricity of $2^{\circ}$, and $25^{\circ}$ at an eccentricity of $10^{\circ}$, but only for cats of a given weight range (Sanderson, 1971b). This problem was solved by making multiple electrode penetrations into the dLGN of animals that previously had received a cortical injection and recording from cells at key locations 
a
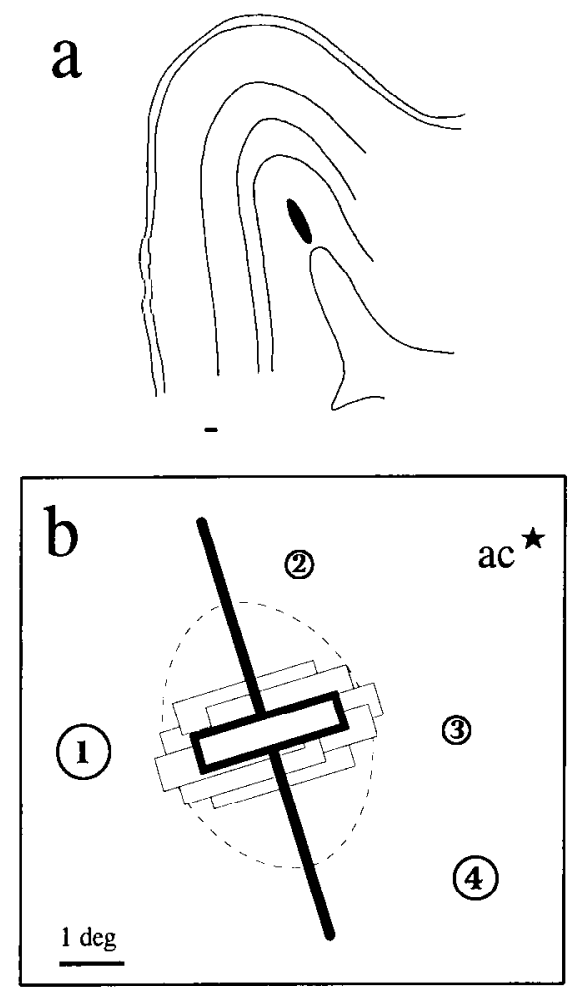

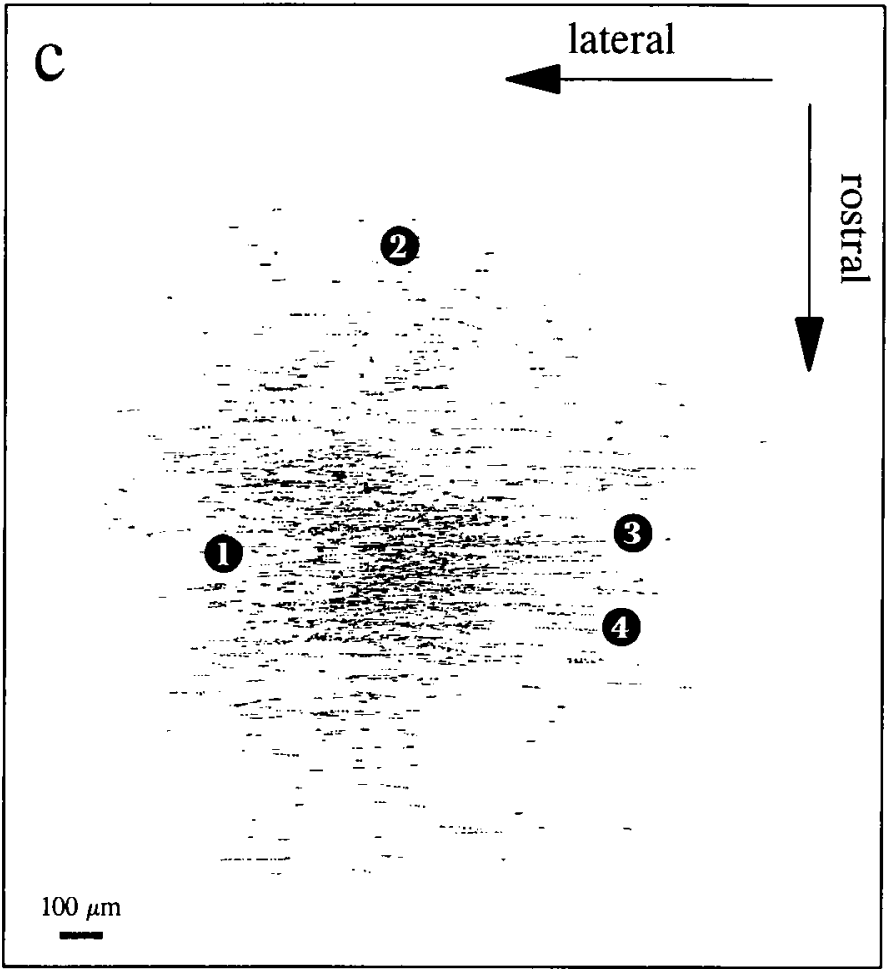

Figure 10. Lateral distribution of terminals arising from a group of corticofugal axons, $a$, The cortical injection site. $b$, Receptive-field map showing the orientation preference and minimum discharge zone for a representative cell at the center of the injection site (bold lines), an aggregate field estimated from the scatter of cortical receptive fields at this eccentricity (fine lines), and an aggregate length summation zone (dotted line). Also shown are the locations of the receptive fields of four dLGN cells $(1-4)$ recorded in and around the corticofugal termination zone and the area centralis (ac). $c$, Dorsal view of the dLGN showing the distribution of boutons arising from the cortical injection site compared with the location of the four geniculate recording sites (1-4). The cortical axons innervate a core region $400-500 \mu \mathrm{m}$ in diameter but have a maximum spread of $1.5 \mathrm{~mm}$. Scale bars, $100 \mu \mathrm{m}$ unless otherwise stated.

within and around the expected termination zone of the labeled corticofugal axons. Recording sites were marked with electrolytic lesions, allowing a direct comparison between known locations within the retinotopic map of individual nuclei and the distribution of stained boutons within the same tissue. For example, Figure $10 a$ shows the location of an extracellular injection that filled 33 pyramidal cells with somata confined to a $100-\mu \mathrm{m}$-wide column in the center of layer VI. Between 6 and 10 of these cells project to the dLGN. The visual receptive field of a representative cell from the injection site is illustrated in Figure $10 \mathrm{~b}$, as is an aggregate field estimated from the known degree of scatter of receptive-ficld locations in this part of the primary visual cortex (Albus, 1975). Typical of the corticofugal population, this cell had a relatively broad but short minimum discharge zone and showed little response summation beyond a bar length of $2^{\circ}$. Note that corticofugal cells show length summation up to an average of only $2.2^{\circ}$ (Grieve and Sillito, 1995), and so the overall field for this injection site would have a maximum diameter of $2-4^{\circ}$. The locations of four dLGN receptive fields lying well outside that region are also shown. The distribution of terminal boutons labeled from the cortical injection site is illustrated in Figure $10 c$. It has a central core region $400-500 \mu \mathrm{m}$ across and a maximum mediolateral extent of $\sim 1.5 \mathrm{~mm}$. This is entirely consistent with the single-axon data. Increasing the size of the injection up to 1 $\mathrm{mm}$ in diameter did not appreciably increase the size of the termination zone. Thus, the terminal fields of individual axons arising from a single cortical locus are closely in register, with very little scatter in their locations. The size and location of the core region correlate very closely with the size and location of the minimum discharge zone of the cortical aggregate receptive field, showing that there is an accurate retinotopic component to the feedback pathway. The overall innervation is far more extensive, however, encompassing each of the four dLGN recording sites and covering a total region $\sim 10^{\circ}$ or more in diameter. The results of these experiments show that the corticofugal system projects to dLGN cells with receptive fields that lie well beyond those of the cortical cells of origin.

\section{DISCUSSION}

We have succeeded in labeling entire axons of the corticofugal feedback pathway, from arca 17 of the cat visual cortex to the $\mathrm{dLGN}$, and have shown them to be both more extensive and more selective than was thought previously. These findings have important implications regarding the capacity of the corticofugal system to mediate long-range lateral interactions at the geniculate level, and they provide a new insight into the mechanisms underlying subcortical binocular integration.

\section{Pattern of innervation within retinotopic space}

The fine structure of type 1 intrageniculate axons was first described by Guillery (1966), who later proved that they are of cortical origin (Guillery, 1967). Since then, attempts have been made to provide a more complete description, but for methodological reasons previous work has been confined primarily to the 
Figure 11. A summary of the pattern of connectivity from the striate cortex to the dLGN. Note that all physical distances have been translated into the equivalent retinotopic distance, calculated for an eccentricity of $5^{\circ}$, and are shown at the same scale as the receptive fields. All are expressed in degrees of visual angle. The figures are appropriate for a constant eccentricity, because the distortion produced by the changing retinotopic magnification factor has been ignored. Top, The receptive fields of three corticofugal cells and a geniculate $X$ cell and a geniculate $Y$ cell. The dimensions of the cortical fields include both minimum discharge and the length summation zones; only the excitatory centers of the geniculate fields are shown. Bottom, Distribution of the intrageniculate terminal arbors arising from the three corticofugal cells, compared with the location and dendritic spread of the $X$-cell and $Y$-cell. Thick and thin solid lines indicate core; thick and thin dashed lines indicate greatest.

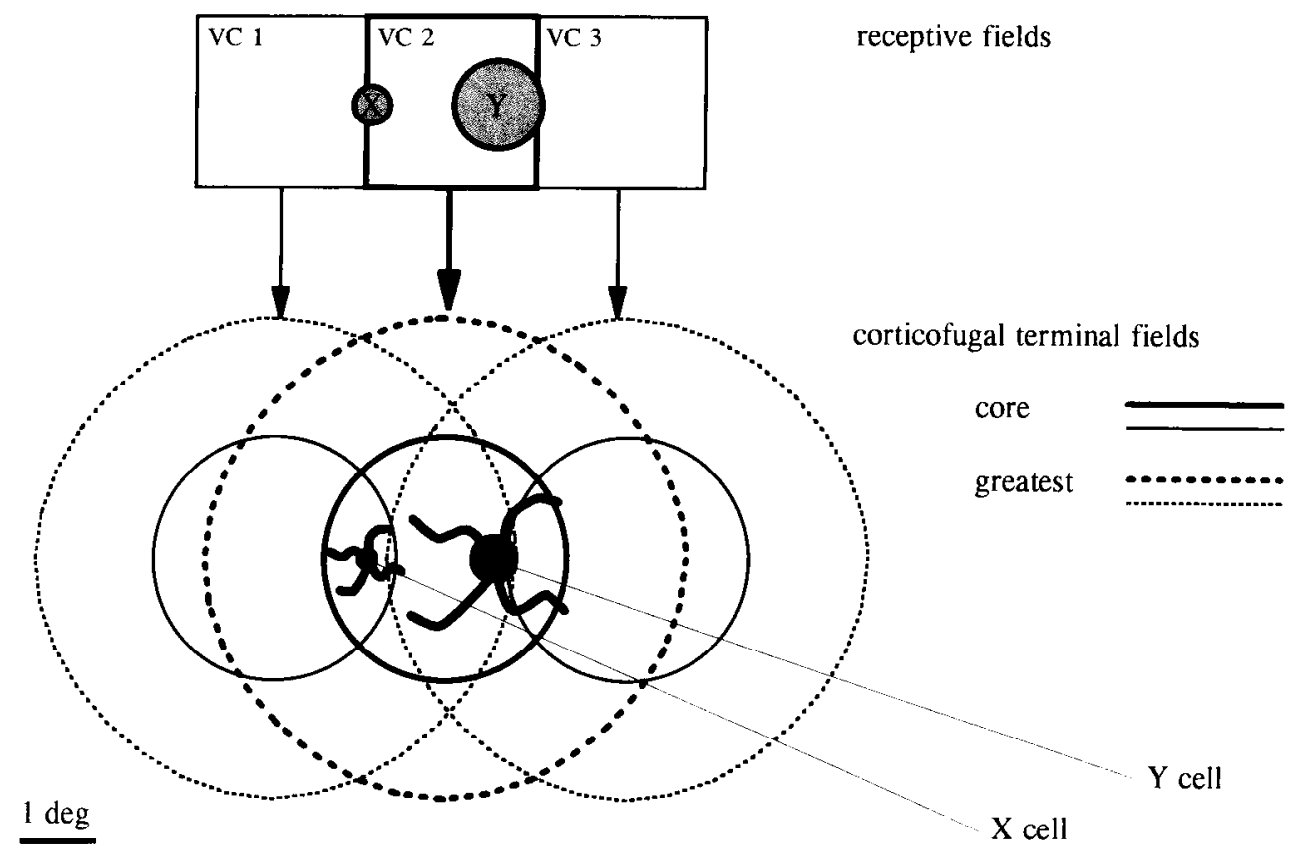

study of single collaterals (Robson, 1983, 1984; Boyapati and Henry, 1984; McCart and Henry, 1994). Early results (Guillery, 1966; Robson, 1983; Boyapati and Henry, 1984) emphasized the fact that these processes tend to take a vertical course through the dLGN, following the lines of the retinotopic projection columns (Sanderson, 1971b). The presence of longer (up to $500 \mu \mathrm{m}$ ), laterally directed collaterals was recognized by Robson (1984), but most side-branches were described as short and bearing few terminal boutons. This implied that each axon would form a tightly knit bundle of processes innervating a narrow column of tissue spanning the depth of the dLGN and that the feedback would be confined to a precise, retinotopically matching region of the visual field.

We have shown that each axon possesses many descending branches spread over a relatively wide area and that a majority of side-branches are extensive and can be traced and reconstructed through many serial sections. The maximum spread of the innervation, as typified by the largest single axon (Fig. 3, right) and by the more global label illustrated in Figure 10 , is $\sim 1.5 \mathrm{~mm}$. This represents an area that exceeds not only the minimum discharge zone of the cells of origin but also the maximum region over which cortico-geniculate cell fields at the corresponding eccentricity summate (Grieve and Sillito, 1995).

The innervation has a more restricted core of relatively dense innervation that matches the location and dimensions of the receptive fields of the cells of origin. In other words, this region is truly retinotopic in that it provides a connection between a given cortical location and the geniculate cells that provide its visual input. Even so, this region has dimensions $(400-500 \mu \mathrm{m})$ that exceed those of either retinal X-cell (average $150 \mu \mathrm{m}$ ) or Y-cell (average $375 \mu \mathrm{m}$ ) axons (Bowling and Michael, 1984), and which will provide an influence from well beyond the center of $\mathrm{X}$ - or Y-type receptive fields.

The situation is summarized in Figure 11, which illustrates the spread of the axonal arborizations of three corticofugal cells with nonoverlapping visual receptive fields, as compared with the dendritic arbors and receptive fields of an $\mathrm{X}$ - and a Y-type dLGN cell.
The diagram is calibrated in terms of visual angle rather than physical distance and is based on average figures for an eccentricity of $\sim 5^{\circ}$ (Sanderson, 1971a,b; Albus, 1975). Thus, for example, the core and maximum diameter of the corticofugal axons (490 and $940 \mu \mathrm{m}$, respectively) cover a visual field angle of $3.3^{\circ}$ and $7^{\circ}$. The core region alone of a single axon is large enough to encompass dLGN cells with nonoverlapping dendritic fields and widely separated excitatory discharge zones. Likewise, the core projection zones arising from cortical cells with adjacent receptive fields overlap one another and may each provide substantial input to a single target. If the entire arborization is taken into account, the degree of convergence is even greater, such that cortical cells with widely spaced receptive fields could influence the activity of a single dLGN cell.

\section{Functional considerations}

The logic for dividing our description between a core and a surrounding zone lies in the correspondence between the region of higher terminal density and a number of physiologically defined measures. We have shown that the core matches the location and dimensions of the aggregate cortical receptive field. This in turn corresponds to the region of visual space over which a corticofugal influence over spatial integration has been shown to summate (Murphy and Sillito, 1987; Grieve and Sillito, 1995), as well as the receptive-field separations within which Tsumoto et al. (1978) demonstrated direct excitatory connections between cortical and geniculate cells. 'Isumoto et al. (1978) also demonstrated inhibitory effects both within and beyond this central region, but this is adequately explained by the fact that the inhibitory pathway is indirect. Thus, the axons of perigeniculate cells in particular will extend the zone of corticofugal influence beyond the range of the associated corticofugal terminals. Taken together, these data suggest that the feedback is capable of exerting an excitatory drive or modifying response selectivity only within the core region.

The far more extensive zone of relatively sparse termination provides input to regions of the visual field from which direct corticofugal influences on single-cell receptive-field properties or 
firing rates have yet to be demonstrated. This suggests that it fulfills a more subtle role and could be involved, for example, in modifying the fidelity (McClurkin et al., 1994) and coherence (Sillito et al., 1994) of the activity of groups of geniculate cells in response to more complex and extensive visual stimuli. It is clear that feedback from a single cortical location must be capable of influencing geniculate cells with widely scattered visual fields and that any point in the dLGN will receive cortical input from cells that encode an equally wide region of visual space. Thus, corticofugal feedback must transmit information relating to global as well as to local information processing. It has been suggested that one function of the pathway is to adjust the activity of dLGN cells, which receive strictly localized retinal information, to reflect the more global picture achieved at higher stages of visual processing (Mumford, 1991; McClurkin el al., 1994; Sillito et al., 1994). Most previous work has focused on the relatively large cortical receptive ficlds as a vehicle for pooling information from beyond the retinal sphere of influence. The wide-ranging corticofugal afferents, however, ensure a far higher degree of spatial convergence than was suspected previously, suggesting that geniculate cells may be sensitive to stimulus context over much longer distances. It is of interest to note that the region of visual space covered by the corticofugal axons in the dLGN corresponds to $\sim 6 \mathrm{~mm}$ in the cortical retinotopic map. This is far greater than the spread of either the intrinsic axons of corticofugal cells or the Y-type geniculo-cortical afferents; however, it does match rather closely the spread of the longest-ranging horizontal intracortical axons (Luhmann et al., 1990) and the cortical point-spread function (Das and Gilbert, 1995).

Even within the core, the distribution of terminal boutons arising from any given axon is extremely diffuse. This contrasts with the organization of retinal afferents, which provide a dense innervation to a narrow column of the dLGN (Bowling and Michael, 1984), and suggests that the corticofugal system has a very different pattern of connectivity. Although retinal axons make multiple contacts onto a small number of targets (Hamos et al., 1987; Mastronarde, 1992), it seems likely that individual cortical afferents will make a small number of synapses onto each of a large pool of postsynaptic cells. Because single dLGN cells can receive $>2000$ cortical synapses (Wilson et al., 1981), it follows that each must acquire convergent input from a large number of corticofugal axons. Those axons will represent a full range (Sillito et al., 1993) of rather narrow orientation and direction selectivities (Harvey, 1980; Grieve and Sillito, 1995), and they have fields that are scattered over several degrees of visual space. It is hardly surprising, therefore, that corticofugal feedback has a relatively subtle effect compared with that of the highly focused retinal input, despite the far greater number of corticofugal synapses on each dLGN cell.

\section{Classification of the axons}

Although our larger injections confirm that the area 17 pathway terminates evenly throughout the depth of the dLGN (Updyke, 1975), the reconstructed axons contribute few boutons to the parvocellular layers. One possible explanation is that we failed to label the most distal branches. This cannot be excluded entirely because the extremities are so fine that they are often difficult to visualize. If it is the case, however, then the lateral spread of the corticofugal axons must also be even greater than we have demonstrated.

An alternative possibility is that the main input to the parvocellular layers stems from axons of type 2 corticofugal cells (Katz,
1987). We failed to label any in this category well enough for reconstruction, presumably because they are too fine $(\leq 0.2 \mu \mathrm{m})$ to transport the biocytin effectively. We know, however, that type 2 cells have intrinsic axons that project to cortical layer $\mathrm{V}$, as do the axons of parvocellular dLGN afferents, whereas type 1 cells connect with the magnocellular recipient layer IV (LeVay and Gilbert, 1976; Katz, 1987). There is some reason, therefore, to believe that types 1 and 2 axons might have a special relationship with the magnocellular and parvocellular pathways, respectively.

It has been suggested that type 1 axons can be divided further and, therefore, that the corticofugal feedback pathway comprises three subgroups (Tsumoto and Suda, 1980; Katz, 1987). Given the variability of our reconstructed axons, all of which belong to the type 1 category, it is possible that they represent a heterogeneous population. We found no evidence for a subdivision based on arbor size or bouton number. The thinner axons, however, are restricted to layers that receive retinal $X$-cell input, whereas the thicker ones, like retinal $\mathrm{Y}$-cells, also project to the $\mathrm{C}$ layers and MIN (Hoffmann and Stone, 1973). Although purely speculative, this is not inconsistent with the possibility that fast, intermediate, and slow axons of the corticofugal pathway could form a specific association with their retinal counterparts.

\section{Eye-specific bias in the innervation}

Corticofugal axons show a substantial bias in their innervation of layers $A$ and $A 1$, which matches the ocular dominance of their cells of origin. This has been demonstrated previously in monkeys using retrograde labeling (Hendrickson et al., 1978), but single collaterals innervating both layers $\mathrm{A}$ and $\mathrm{Al}$ made it seem unlikely in the cat (Guillery, 1966; Robson, 1983; Boyapati and Henry, 1984). We now know that corticofugal axons arising from within or near the center of an ocular dominance column have 3 times as many synaptic boutons in the layer that shares their eye prefer ence, and from which their main afferent input derives, as they do in the inappropriate layer. Interestingly, the inhibitory perigeniculate feedback pathway also has an eye-specific bias (Uhlrich et al., 1991).

These results are entirely consistent with the physiology of identified area 17 corticofugal cells, of which more than half are entirely monocular and a majority of the rest are strongly biased toward one or the other eye (Grieve and Sillito, 1995). This is a far higher degree of selectivity than that of the layer VI cell population as a whole, suggesting that segregation of the information arising from the two eyes is functionally important. The fact that this functional specificity is matched by a high degree of target selectivity suggests that the extent to which dLGN cells receive nondominant eye input via the cortex is far more limited than assumed previously. Thus, it is no longer surprising that the cortex seems incapable of driving them through the inappropriate eye alone (Murphy and Sillito, 1989). The corticofugal system does influence binocular interactions within the dLGN (Schmeilau and Singer, 1977; Varela and Singer, 1987; Murphy and Sillito, 1989), but perhaps this is attributable more to the binocular interactions established within the cortex itself than to the relatively sparse nondominant eye inputs to dLGN cells.

\section{REFERENCES}

Adams JC (1981) Heavy metal intensification of DAB-based HRP reaction product (Abstr). J Histochem Cytochem 29:775A.

Ahlsen G, Grant K, Lindstrom S (1982) Monosynaptic excitation of principal cells in the LGN by corticofugal fibres. Brain Res $234: 454-458$ 
Albus K (1975) A quantitative study of the projection area of the central and paracentral visual field in area 17 of the cat. I. The precision of the topography. Exp Brain Res 24:159-179.

Allman JM, Miezen F, McGuiness E (1985) Stimulus specific responses from beyond the classical receptive field: neurophysiological mechanisms for local-global comparisons in visual neurons. Annu Rev Neurosci $8: 407-430$.

Bowling DB, Michael CR (1984) Terminal patterns of single, physiologically characterized optic tract fibers in the cat's lateral geniculate nucleus. J Neurosci 4:198-216.

Boyapati J, Henry GH (1984) Corticofugal axons in the lateral geniculate nucleus of the cat. Exp Brain Res 53:335-340.

Das A. Gilbert CD (1995) Long-ranging horizontal connections and their role in cortical reorganization revealed by optical recording of cat primary visual cortex. Nature 375:780-784.

Deschenes M, Pinault D (1993) A method of complete staining of identified neurons at will. Soc Neurosci Abstr 19:545.

Grieve KL, Sillito AM (1995) Differential properties of cells in the feline primary visual cortex providing the corticofugal feedback to the lateral geniculate nucleus and visual claustrum. J Neurosci 15:4868-4874.

Guillery RW (1966) A study of Golgi impregnations from the dorsal lateral geniculate nucleus of the adult cat. J Comp Neurol 128:21-50.

Guillery RW (1967) Patterns of fibre degeneration in the dorsal lateral geniculate nucleus of the cat following lesions in the visual cortex. $\mathbf{J}$ Comp Neurol 130:197-222.

Hamos JE, Van Horn SC, Raczkowski D, Sherman SM (1987) Synaptic circuits involving an individual retinogeniculate axon in the cat. J Comp Neurol 259:165-192.

Harvey AR (1980) A physiological analysis of subcortical and commissural projections of area 17 and 18 of the cat. J Physiol (Lond) 302:507-534.

Hendrickson AE, Wilson JR, Ogren MP (1978) The neuroanatomical organization of pathways between the dorsal lateral geniculate nucleus and the visual cortex in old and new world primates. J Comp Neurol 182:123-136.

Hoffmann K-P, Stone J (1973) Central termination of W-, X-, and Y-type ganglion cell axons from cat retina. Brain Res 49:500-501.

Höllander $\mathrm{H}$ (1972) Autoradiographic evidence for a projection from the striate cortex to the dorsal part of the lateral geniculate nucleus in the cat. Brain Res 41:464- 466 .

Horikawa K, Armstrong WE (1988) A versatile means of intracellular labeling: injection of biocytin and its detection with avidin conjugates. $\mathrm{J}$ Neurosci Methods 25:1-11.

Katz LC (1987) Local circuitry of identified projection neurons in cat visual cortex brain slices. J Neurosci 7:1223-1249.

LeVay S, Gilbert CD (1976) Laminar patterns of geniculocortical projection in the cat. Brain Res 113:1-19.

Luhmann HJ, Singer W, Martínez-Millán L (1990) Horizontal interactions in cat striate cortex. I. Anatomical substrate and postnatal development. Eur J Neurosci 2:344-357.

Marrocco RT, McClurkin JW, Young RA (1982) Modulation of lateral geniculate nucleus cell responsiveness by visual activation of the corticogeniculate pathway. J Neurosci 2:256-263.

Mastronarde DN (1992) Nonlagged relay cells and interneurons in the cat lateral geniculate nucleus: receptive-field properties and retinal inputs. Vis Neurosci 8:407-441.

McCart RJ, Henry GH (1994) Visual corticogeniculate projections in the cat. Brain Res 653:351-356.

McClurkin JW, Optican LM, Richmond BJ (1994) Cortical feedback increases visual information transmitted by monkey parvocellular lateral geniculate nucleus neurons. Vis Neurosci 11:601-617.

Montero VM (1989) Ultrastructural identification of synaptic terminals from cortical axons and from collateral axons of geniculo-cortical relay cells in the perigeniculate nucleus of the cat. Exp Brain Res 75:65-72.
Montero VM (1991) A quantitative study of synaptic contacts on interneurons and relay cells of the cat lateral geniculate nucleus. Exp Brain Res 86:257-270.

Mumford D (1991) On the computational architecture of the neocortex. I. The role of the thalamo-cortical loop. Biol Cybern 65:135-145.

Murphy PC, Sillito AM (1987) Corticofugal feedback influences the generation of length tuning in the visual pathway. Naturc 329:727-729.

Murphy PC, Sillito AM (1989) The binocular input to cells in the feline dorsal lateral geniculate nucleus (dLGN). I Physiol (Lond) 415:393-408.

Murphy PC, Grieve KL, Sillito AM (1993) Effects of vasoactive intestinal polypeptide on the response properties of cells in area 17 of the cat visual cortex. J Neurophysiol 69:1465-1474.

Robson JA (1983) The morphology of corticofugal axons to the dorsal lateral geniculate nucleus in the cat. I Comp Neurol 216:89-1013.

Robson JA (1984) Reconstruction of corticogeniculate axons in the cat. J Comp Neurol 225:193-200.

Sanderson KJ (1971a) Visual projcction columns and magnification factors in the lateral geniculate nucleus of the cat. Exp Brain Res 13:159-177.

Sanderson KJ (1971b) The projection of the visual ficld to the lateral geniculate and medial interlaminar nuclei in the cat. J Comp Neurol 143:101-118.

Schmeilau F, Singer W (1977) The role of visual cortex for binocular interactions in the cat lateral geniculate nucleus. Brain Res $120: 354-361$.

Sillito AM, Cudeiro J, Murphy PC (1993) Orientation sensitive elements in the corticofugal influence on centre-surround interactions in the dorsal lateral geniculate nucleus. Exp Brain Res 93;6-16.

Sillito AM, Jones HE, Gerstein GL, West DC (1994) Feature-linked synchronization of thalamic relay cell firing induced by feedback from the visual cortex. Nature 369:479-482.

Tsumoto T, Suda K (1980) Three groups of cortico-geniculate neurons and their distribution in binocular and monocular segments of cat striate cortex. J Comp Neurol 193:223-236.

Tsumoto T, Creutzfeldt OD, Légendy CR (1978) Functional organization of the corticofugal system from visual cortex to lateral geniculate nucleus in the cat. Exp Brain Res 32:345-364.

Tusa RJ, Palmer LA, Rosenquist AC (1978) The retino-topic organization of arca 17 (striatc cortex) in the cat. J Comp Neurol 177:213-236.

Uhlrich DJ, Cucchiaro JB, Humphrey AL, Sherman SM (1991) Morphology and axonal projection patterns of individual neurons in the cat perigeniculate nucleus. J Neurophysiol 65:1528-1541.

Updyke BV (1975) The patterns of projection of cortical areas 17, 18, and 19 onto the laminae of the dorsal lateral geniculate nucleus in the cat. J Comp Neurol 163:377-396.

Updyke BV (1977) Topographic organization of the projections from cortical areas 17-19 onto the thalamus, pretectum and superior colliculus in the cat. J Comp Neurol 173:81-122.

Varela FJ, Singer W (1987) Neuronal dynamics in the visual corticothalamic pathway revealed through binocular rivalry. Exp Brain Res 66:10-20.

Vidnyánszky Z, Hámori J (1994) Quantitative electron microscopic analysis of synaptic input from cortical areas 17 and 18 to the dorsal lateral geniculate nucleus in cats. J Comp Neurol 349:259-268.

Weber AJ, Kalil RE (1987) Development of corticogeniculate synapses in the cat. J Comp Neurol 264:171-192.

Weber AJ, Kalil RE, Behan M (1989) Synaptic connections between corticogeniculate axons and interneurons in the dorsal lateral geniculate nucleus of the cat. J Comp Neurol 289:156-164.

Wilson JR, Friedlander MJ, Sherman SM (1984) Fine structural morphology of identified $\mathrm{X}$ - and $\mathrm{Y}$-cells in the cat's lateral geniculate nucleus. Proc R Soc Lond [Biol] 221:411-436. 